\title{
Evaluation of a Peer-Led Asthma Self-Management Program and Benefits of the Program for Adolescent Peer Leaders
}

\author{
Hyekyun Rhee PhD PNP, Brenda E McQuillan LMSW, and Michael J Belyea PhD
}

\begin{abstract}
BACKGROUND: Asthma is the leading chronic condition in adolescents. Nonetheless, research efforts to address adolescent asthma morbidity by applying a developmentally appropriate selfmanagement intervention have been limited. Recently a peer-led asthma self-management program has been developed and implemented for adolescents. The purpose of the study was to assess the acceptability of a peer-led asthma program for adolescents based on participant feedback and to examine the program's impact on asthma outcomes in peer leaders. METHODS: Adolescents with persistent asthma ( $n=91,13-17$ years) participated in a camp-based asthma program led by peer leaders (the intervention group) or healthcare professionals (the control group), and completed a set of program evaluation forms. Peer leaders $(n=14,16-20$ years) completed study questionnaires measuring asthma knowledge, self-efficacy, asthma control, and quality of life at baseline, immediately after camp, and 3, 6, and 9 months post-camp. RESULTS: The peer-led group reported more positive experience with the program than the adult-led group $(P=.01$, Cohen's $d=0.53)$, particularly in its usefulness in dealing with asthma. Peer leaders were rated by participants highly on knowledge (98\%), attitudes (93-96\%), personal skills $(91 \%)$, and perceived similarities $(80-$ $86 \%)$. Significant improvements were found in peer leaders' knowledge $\left(P<.001, \eta^{2}=0.87\right)$, self-efficacy $\left(P<.001, \eta^{2}=0.74\right)$, asthma control $\left(P=.01, \eta^{2}=0.66\right)$, and quality of life in emotional functioning $\left(P=.002, \eta^{2}=0.82\right)$ and activity $\left(P=.003, \eta^{2}=0.62\right)$. CONCLUSIONS: A peer-led asthma self-management program was successfully implemented and well received by adolescent learners. Asthma outcomes in peer leaders appear to have improved as a result of the program, although caution should be exercised in determining clinical meaningfulness, given the modest changes in mean scores. ClinicalTrials.gov registration NCT01161225. Key words: asthma; adolescents; self-management; peer-led program; peer leaders. [Respir Care 2012;57(12):2082-2089. (c) 2012 Daedalus Enterprises]
\end{abstract}

\section{Introduction}

Effects of a health education targeting adolescents' attitudes and behaviors greatly depend on characteristics of the individuals who provide education. Adolescents' ability to closely associate with their educators maximizes this

\footnotetext{
Dr Rhee and and Ms McQuillan are affiliated with the School of Nursing, University of Rochester, Rochester, New York. Dr Belyea is affiliated with the College of Nursing and Health Care Innovation, Arizona State University, Phoenix, Arizona.
}

This study was supported by National Institutes of Health/National Institute of Nursing Research grant R21 NR009837, awarded to Hyekyun Rhee.

The authors have disclosed no conflicts of interest. effect. ${ }^{1,2}$ Adolescents are more likely to promote positive attitudes and enact modeled behaviors when they perceive the models as similar to themselves. ${ }^{3}$ Adolescents tend to seek guidance from those who are similar on salient dimensions, and the opinions of the similar others are more influential than those of dissimilar others. ${ }^{4}$ Thus, it is nat-

\footnotetext{
Dr Rhee presented a version of this paper at the annual meeting of the Eastern Nursing Research Society, held March 24-26, 2010, in Providence, Rhode Island.

Correspondence: Hyekyun Rhee PhD PNP, School of Nursing, University of Rochester, 601 Elmwood Avenue, Box SON, Rochester NY 14642. E-mail: hyekyun_rhee@urmc.rochester.edu.
}

DOI: $10.4187 /$ respcare. 01488 
ural that adolescents with chronic illness will highly value support from peers with the same chronic illness. Aside from greater ease in conversing about illness, the adolescents perceive that peers with chronic health conditions can really understand and provide support. ${ }^{5}$ Peer identification through interactions with peers with asthma allows adolescents with asthma to become aware that they are not alone, alleviating feelings of isolation and fostering a sense normalcy. ${ }^{6,7}$ The ability to openly discuss illness with other peers can also positively influence asthma self-management in adolescents. ${ }^{8}$ Having recognized the importance of peers, previous studies have adopted a peer leader approach in implementing programs addressing a variety of health issues in adolescents and found it effective in obtaining desired health outcomes. ${ }^{9-13}$ Peer leaders who share similarities with learners are considered "insiders" who can sympathize with the learners' perspectives and experiences, thus best situated to address health issues and challenges facing adolescents. In a systematic review of the literature, Mellanby et $\mathrm{al}^{14}$ concluded that peer-led health programs were superior to adult-led programs in enhancing knowledge and positive attitudes and changing behaviors of adolescents.

Peer leader programs can be beneficial to peer leaders as well as adolescent learners. Through training, leaders can develop a wide range of inter- and intra-personal skills in presenting and communicating information and strategies for supporting others. ${ }^{15}$ Peer leader training and experience can be effective in promoting the leaders' cognitive gains (knowledge), affective gains (attitudes and emotions), and social gains (understanding about others), ${ }^{16}$ as well as in yielding positive changes in their own health behaviors. ${ }^{1,9,15-19}$

An asthma program adopting a peer leader approach was implemented in school settings in Australia and found to be effective in improving quality of life in adolescents who received the program. ${ }^{20}$ However, the study was limited in providing comprehensive evaluation of the program from the learners' perspective and the extent to which peer leaders benefited from the program. We recently completed a study evaluating a peerled asthma self-management program for adolescents implemented within a day-camp setting. The effectiveness of the program in improving asthma outcomes in adolescent learners has been reported elsewhere. ${ }^{21}$ The specific aims of this study were to assess participants' acceptability of the program and peer leaders as indicated on evaluation measures, and to determine the program's effects on peer leader's asthma outcomes, including asthma knowledge, self-efficacy, quality of life, and asthma control.

\section{QUICK LOOK}

\section{Current knowledge}

Asthma is the leading chronic respiratory disease in adolescents. Research efforts to address adolescent asthma morbidity by applying a developmentally appropriate self-management intervention have been widely studied. Adolescence is an important period for asthma self-management training, as daily responsibilities of disease management are gradually transferred from parents to adolescents.

\section{What this paper contributes to our knowledge}

A peer-leader approach is an alternative to conventional asthma management programs offered by health professionals, and is well received by adolescents. Adolescents with asthma, after adequate training, can serve as leaders who can assist their peers with asthma. Clinician involvement is necessary to identify and train qualified peer leaders.

\section{Methods}

\section{Design}

This was part of a randomized controlled study that evaluated the effectiveness of a peer-led asthma self-management program for adolescents. Participants' acceptability of the program was assessed based on program evaluation data obtained from adolescent participants who were randomly assigned to either the intervention or control group, based on a computer generated random table. The effects of the program on asthma outcomes in peer leaders were examined using data collected at 5 time points: baseline, immediately after the camp, and 3, 6, and 9 months after the camp.

\section{Sample and Settings}

Eligibility criteria for the peer leaders included: (1) age 16-20 years, (2) nomination from teachers or healthcare providers, (3) good academic standing (grade point B or above), (4) mild to severe persistent asthma, (5) physician diagnosed asthma for $\geq 1$ year, (6) ability to understand spoken and written English, and (7) absence of other chronic illness or mental health concerns. Inclusion criteria for program participants (ie, campers) were ages 13-17 years and above criteria 4-7. To determine the persistent asthma status we developed an asthma classification checklist consisting of 4 questions based on the National Heart Lung and Blood Institute asthma guidelines. ${ }^{22}$ The checklist asked 
Table 1. Peer Leader Characteristics $(n=14)$

\begin{tabular}{lc}
\hline \hline Age, mean $\pm \mathrm{SD}$ & $17.6 \pm 1.74$ \\
Female & $11(79)$ \\
Male & $3(21)$ \\
White & $10(71)$ \\
Non-white & $4(29)$ \\
Family annual income & \\
$\quad<\$ 30,000$ & $4(28.6)$ \\
$\quad \$ 30,000-\$ 69,999$ & $4(28.6)$ \\
$\geq \$ 70,000$ & $6(42.9)$ \\
& \\
\hline Values are number and percent unless otherwise indicated. & \\
\hline
\end{tabular}

about daytime symptoms, night-time symptoms, quick relief mediation use, and activity limitation experienced by potential participants in the past 4 weeks. Persistent asthma was determined when adolescents reported daytime symptoms $>2$ days/week, $>3-4$ times night-time awakening due to asthma in the past 4 weeks, using quick relief medication $>3$ days per week, or any interference with daily activities due to asthma in the past 4 weeks. In addition, an adolescent who reported use of a control medication was considered eligible regardless of the outcomes of the checklist.

Most peer leaders were referred and nominated by healthcare providers and school nurses. We screened 22 adolescents, of whom 6 were ineligible and 2 dropped out due to time conflicts. Subsequently, 14 were enrolled as peer leaders; Table 1 summarizes the demographic characteristics of the peer leaders.

\section{Intervention}

Fourteen peer leaders attended a 3-week training session (4-5 h/week) provided by a nurse practitioner. Training modules were primarily based on the Power Breathing program ${ }^{23}$ and included: basic asthma education on pathophysiology and triggers; psychosocial issues of asthma; and asthma monitoring and treatment. Training on leadership skills was also provided. Peer leaders were paired to lead small groups of 6-8 participants at the asthma day camp, attended by 44 adolescents with asthma, ages 1317 years. Small groups were assigned based on participants' age (13-14 years vs 15-17 years) and sex. Details of the intervention are provided elsewhere. ${ }^{21}$

\section{Evaluation Measures}

Camp Program Evaluation (7 items), constructed for the study was administered to all participants after camp to assess the campers' perceptions about the program. Each item was measured on a 5-point scale ( $1=$ strongly agree, to $5=$ strongly disagree). Higher scores indicated more positive evaluation. Cronbach alpha was 0.84. Percentage of positive responses ("strongly agree" and "agree") was examined for each item.

Overall Program Evaluation (6 items) was completed by all participants at 9-months follow-up, to measure overall perceptions about the study. For peer leaders we added 2 questions to capture their experiences (ie, being peer leaders and making monthly contacts with the campers) with the study.

Peer Leaders Rating Scale (8 items): Ozer et al ${ }^{1}$ developed the scale to measure adolescents' perceptions about their peer educators' characteristics essential to a peer-led program. The scale, which was originally developed for a human immunodeficiency virus/acquired immune deficiency syndrome (HIV/AIDS) prevention program was revised by substituting "asthma" for "HIV/AIDS" and eliminating an item deemed irrelevant for the current study. The teens responded to a 4-point scale ranging from "definitely true" to "definitely not true" for items measuring "positive regard" (ie, warmth, expertise, and credibility), and "perceived similarity." Lower scores indicated more positive ratings of peer leaders. The scale was completed immediately after the camp. The Cronbach alpha was 0.75 in the current sample.

Perceived Peer Leader Support Scale (10 items) was completed by peer-led camp participants at 9-month follow-up to measure perceived support from peer-leaders. The scale was the modification of Perceived Social Support from Friends. ${ }^{24}$ Higher scores indicated greater perceptions of support. Cronbach alpha was 0.87 in this sample.

\section{Program Outcome Measures in Peer Leaders}

Asthma Knowledge was assessed using a modification of an existing children's asthma knowledge questionnaire. ${ }^{25}$ Our revised version consisted of 30 items presenting brief scenarios involving asthma triggers, symptom identification, and asthma management, for which participants responded on a yes/no scale. A total score was calculated by summing correct answers so that higher total scores indicate higher asthma knowledge. The Cronbach alpha was 0.62 in this sample.

Child Asthma Self-Efficacy, consisting of 14-items (5point scale), measured adolescents' confidence in attack prevention (eg, learn asthma self-management skills, correct use of medication) and attack management (eg, control symptoms, decide which medication to use). ${ }^{26}$ Evidence of construct validity was demonstrated, ${ }^{27}$ and Cronbach alpha was 0.83 in the current sample.

Asthma Control Questionnaire was constructed to measure 4 areas of asthma-related impairment, as recommended by the National Heart Lung and Blood Institute guidelines. ${ }^{22}$ The types of impairment include daytime symp- 
toms, night-time symptoms, level of activity limitation, and frequency of using short-acting $\beta$ agonists. The 4 items were measured on a 4-point scale, and higher values indicate higher levels of asthma control. The Cronbach alpha was 0.71 .

Pediatric Asthma Quality of Life Questionnaire consisted of 23 items covering problems identified as being most important and troublesome in everyday life due to asthma. ${ }^{28}$ This scale has been found to be sensitive in capturing changes in the varying degree of asthma status. ${ }^{28-30}$ The scale comprises 3 subscales, including symptoms (10 items), emotional function (8 items), and activity limitation ( 5 items). For this paper, the results from the symptom subscale are not reported, to avoid redundancy, given its conceptual overlap with the Asthma Control Questionnaires. Each item was measured on a 7-point scale. Higher total scores indicated better levels of functioning. In this study, the Cronbach alphas of the 2 subscales were 0.93 (emotional functioning) and 0.84 (activity).

\section{Procedures}

Fourteen peer leaders completed baseline data at enrollment; 13 attended 3-week training sessions. One peer leader failed to participate in the asthma camp, due to an illness. Peer leaders were paired and assigned to lead 6 small groups of 6-8 adolescent participants who attended a day asthma camp. Peer leaders led interactive asthma selfmanagement sessions addressing knowledge and skills essential to self-management and asthma-related psychosocial issues pertaining to adolescence. Efforts were made to foster informal peer relationships between the peer leaders and their group members through recreational activities and group meal times. After camp the peer leaders contacted their group members on the telephone each month for 8 months, to offer support and encouragement. Peer leaders successfully reached about $49 \%$ of the campers each month, and spoke with them for 2-5 min on average for each contact.

The control group also attended a day camp that was comparable to the peer-led camp in regard to the content and length of the program; however, the content was delivered by adult instructors, including 2 nurse practitioners and a physician. Both group participants completed the camp program evaluation at the conclusion of the camp program, and the overall program evaluation at 9 months after the camp. In addition, those who attended the peerled asthma camp completed the peer leaders rating scale immediately after the camp and the perceived peer leader support scale at 9 months after the camp.

Peer leaders completed a set of questionnaires assessing psychosocial and asthma morbidity outcomes at baseline, immediately after camp, and 3, 6, and 9 months postcamp. Informed parent consent and adolescent assent or consent (for those $\geq 18$ years) were obtained prior to the implementation of study procedure. The study protocol was approved by the institutional review board within the medical center affiliated with the researchers.

\section{Data Analysis}

Descriptive analysis was conducted to summarize the evaluation data from the camp participants. Means and SDs were computed, and frequency analysis was performed whenever appropriate. $t$ tests were conducted to compare the total score of camp program evaluation between the peer-led and adult-led groups. Using linear mixed models, repeated measures analysis of variance was conducted for peer leader knowledge, self-efficacy, asthma control, and quality of life as a function of time. Effect sizes of the findings showing significant overall changes in outcome measures were evaluated by computing partial $\eta^{2}$, with $\eta^{2}<0.06$ indicating small, $\eta^{2}=0.06-0.14$ medium, and $\eta^{2}>0.14$ large effects. ${ }^{31}$ Planned contrasts were constructed in order to test changes between time points. Effect sizes for changes between time points were computed using the formula for Cohen's d. ${ }^{31}$ Meaningful change was operationalized as at least half an SD change over time. . $^{32,33}$

\section{Results}

\section{Program Evaluation}

Evaluation measures were obtained anonymously from the camp participants immediately after the camp and at 9 months post-camp. The peer-led group reported a higher total score for camp program evaluation, indicating more positive experiences with the camp than the adult-led group $(P=.01$, Cohen's $\mathrm{d}=0.53)$. Subsequently, we computed the rates of positive responses (strongly agree or agree) for individual items for both groups (Table 2). Although both groups rated similarly in some items, the peer-led group responded more positively in the items indicating acceptability such as "fun" (91\% vs 59\%) and "satisfaction" ( $96 \%$ vs $74 \%$ ) with the camp and potential for personal referral ( $84 \%$ vs $63 \%)$.

In the overall program evaluation collected at 9 months after camp, the 2 groups were not significantly different in their responses to each item (Table 3). In open-ended questions, participants in both groups listed "learning about asthma" and the camp setting as the most liked aspects of the program. Almost twice as many participants in the peer-led group stated that they enjoyed the program than those in the adult-led group. Many adolescents in both groups concurred that meeting with other teens with asthma and "similar issues and struggles" was the most appealing part of the program. 


\section{Evaluation of a Peer-Led Asthma Self-Management Program}

Table 2. Rates of Agreement on Camp Program Evaluation Items*

\begin{tabular}{|c|c|c|c|}
\hline & $\begin{array}{l}\text { Peer-Led } \\
\text { Group } \\
(n=46)\end{array}$ & $\begin{array}{l}\text { Adult-Led } \\
\text { Group } \\
(n=45)\end{array}$ & $P$ \\
\hline I am satisfied with the camp. & $42(95.5)$ & $34(73.9)$ & .006 \\
\hline $\begin{array}{l}\text { I can use things learned from the } \\
\text { camp in managing my asthma. }\end{array}$ & $42(95.5)$ & $41(89.1)$ & .28 \\
\hline The camp was well organized. & $40(90.9)$ & $39(84.8)$ & .40 \\
\hline The camp was fun. & 40 (90.9) & $27(58.7)$ & .001 \\
\hline I learned a lot about asthma at the camp. & $39(88.6)$ & $38(82.6)$ & .44 \\
\hline $\begin{array}{l}\text { I have the opportunity to get to know } \\
\text { other teens with asthma at the camp. }\end{array}$ & $39(88.6)$ & $38(82.6)$ & .26 \\
\hline I would recommend this camp to a friend. & $37(84.1)$ & $29(63.0)$ & .03 \\
\hline
\end{tabular}

Table 3. Rates of Agreement on Overall Program Evaluation Items*

\begin{tabular}{|c|c|c|c|}
\hline & $\begin{array}{c}\text { Peer-Led } \\
\text { Group } \\
(n=43)\end{array}$ & $\begin{array}{c}\text { Adult-Led } \\
\text { Group } \\
(n=41)\end{array}$ & $P$ \\
\hline I learned a lot about asthma from this study. & $41(95.3)$ & $39(95.1)$ & .96 \\
\hline $\begin{array}{l}\text { I have been using information learned from } \\
\text { the study in dealing with my asthma. }\end{array}$ & $41(95.3)$ & $36(87.8)$ & .21 \\
\hline $\begin{array}{l}\text { I feel more confident in handling an asthma } \\
\text { attack when it occurs. }\end{array}$ & $41(95.3)$ & $36(87.8)$ & .21 \\
\hline I have enjoyed participating in this study. & $40(93.0)$ & $41(100)$ & .09 \\
\hline $\begin{array}{l}\text { Since camp, this study has not required too } \\
\text { much of my time. }\end{array}$ & $36(83.7)$ & $32(78.1)$ & .51 \\
\hline $\begin{array}{l}\text { I don't feel as bad as I used to about living } \\
\text { with asthma. }\end{array}$ & $31(72.1)$ & $25(61.0)$ & .28 \\
\hline $\begin{array}{l}\text { Values are number and percent. } \\
* n=84 \text {. }\end{array}$ & & & \\
\hline
\end{tabular}

Those who attended the peer-led camp rated their perceptions about the peer leaders' quality on the peer leaders rating scale (Table 4). Overall, peer leaders were rated highly on knowledge, attitudes, personal skills, and perceived similarities. In the perceived peer leader support scale, the majority of participants rated positively about peer leaders' information support as they responded that peer leaders shared good ideas to deal with asthma $(74.4 \%)$ and were helpful in solving problems related to asthma $(72 \%)$. Fewer participants perceived emotional support from peer leaders $(53.5 \%)$ and reported their reliance on peer leaders' emotional support (51\%). In communication, participants perceived the peer leaders as good listeners (70\%), open $(51 \%)$, sensitive $(61 \%)$, and making the teen comfortable in confiding $(56 \%)$.

All peer leaders responded that they enjoyed being leaders. In written comments, peer leaders indicated their positive experiences as leaders, which allowed them to share their knowledge and experiences with the participants and
Table 4. Rates of Agreement on Peer Leaders' Quality Perceived by Participants*

\begin{tabular}{ll}
\hline \hline My peer leader knows a lot. & $43(97.7)$ \\
She/he has a good sense of humor & $42(95.5)$ \\
She/he believes in what she/he taught us. & $41(93.2)$ \\
She/he seems like someone with whom I could talk. & $40(90.9)$ \\
Before she/he was trained, she/he had the same kind & $38(86.4)$ \\
$\quad$ of attitudes about asthma as I do. & $35(79.5)$ \\
Before trained, she/he had the same kind of attitudes & \\
$\quad$ about taking asthma medication as I do. & $29(65.9)$ \\
$\begin{array}{l}\text { She/he has a life a lot like mine. } \\
\text { She/he is physically attractive. }\end{array}$ & $26(59.1)$ \\
& \\
Values are number and percent. &
\end{tabular}

be a positive role model to other teens with asthma. For instance, a peer leader stated "having the kids at the camp look up to you as a friend and also as a source of information on not only asthma but also simply life" as the most enjoyable aspect of being a peer leader. The majority of the peer leaders (90\%) also commented that the most difficult aspect of being a leader was completing the monthly telephone calls.

\section{Program Effects on Peer Leaders}

During the 9-month post-camp period, one peer leader withdrew from the study because of a family related situation, and one was lost to follow-up. Mixed models analysis of variances revealed significant increases over time in the outcome measures for the peer leaders. Table 5 shows the means and $95 \%$ CIs of each outcome variable for each time point. Peer leaders' knowledge improved significantly over time $\left(P<.001, \eta^{2}=0.87\right)$, particularly from camp to 3 months $(P=.01$, mean difference $=0.90$, $\mathrm{d}=2.85$ ). Significant time effects were also found for asthma-related self-efficacy, which increased over time $\left(P<.001, \eta^{2}=0.74\right)$ with the greatest increase shown from baseline to camp $(P=.003$, mean difference $=6.18$, $\mathrm{d}=3.66)$ and a significant decline from camp to 3 months $(P=.049$, mean difference $=-1.25, \mathrm{~d}=2.16)$. Quality of life also improved throughout the course of study participation for the total scores $\left(P=.03, \eta^{2}=0.57\right)$ and both the emotional functioning $\left(P=.002, \eta^{2}=0.82\right)$ and activity $\left(P=.003, \eta^{2}=0.62\right)$ subscales. The most notable increase was found between the camp and 3-month follow-up (emotion subscale $P=.002$, mean difference $=5.70, \mathrm{~d}=3.76$; activity subscale $P=.003$, mean difference $=4.70, \mathrm{~d}=3.62$ ). Asthma control in the peer leaders also showed steady improvement over time $\left(P=.01, \eta^{2}=0.66\right)$. It is noteworthy that the scores of all outcome measures uniformly improved from baseline 


\section{Evaluation of a Peer-Led Asthma Self-Management Program}

Table 5. Outcomes in Peer Leaders $(n=14)$

\begin{tabular}{|c|c|c|c|c|c|c|c|c|c|c|}
\hline & \multicolumn{2}{|c|}{ Baseline } & \multicolumn{2}{|c|}{ Immediately After Camp } & \multicolumn{2}{|c|}{3 Months After Camp } & \multicolumn{2}{|c|}{6 Months After Camp } & \multicolumn{2}{|c|}{9 Months After Camp } \\
\hline & Mean \pm SD & $95 \% \mathrm{CI}$ & Mean \pm SD & $95 \% \mathrm{CI}$ & Mean \pm SD & $95 \% \mathrm{CI}$ & Mean \pm SD & $95 \% \mathrm{CI}$ & Mean \pm SD & $95 \% \mathrm{CI}$ \\
\hline Asthma knowledge & $26.57 \pm 2.31$ & $25.24-27.91$ & $27.00 \pm 1.65^{*}$ & $25.95-28.05$ & $27.90 \pm 1.29 *$ & $26.98-28.82$ & $27.80 \pm 1.69$ & $26.59-29.01$ & $28.11 \pm 1.45$ & $27.00-29.23$ \\
\hline Asthma self-efficacy & $51.57 \pm 6.45 \dagger$ & $47.85-55.30$ & $57.75 \pm 6.11+\neq$ & $53.87-61.63$ & $56.50 \pm 5.28 \ddagger$ & $52.73-60.27$ & $56.70 \pm 2.63$ & $54.82-58.58$ & $57.44 \pm 3.84$ & $54.49-60.40$ \\
\hline \multicolumn{11}{|c|}{ Quality of Life } \\
\hline Total & $116.57 \pm 36.90$ & $95.23-137.88$ & $124.08 \pm 24.99 \S$ & $108.21-139.96$ & $138.40 \pm 11.05 \S$ & $130.50-146.30$ & $137.10 \pm 15.56$ & $125.97-148.23$ & $138.11 \pm 16.44$ & $125.47-150.75$ \\
\hline Emotion & $45.36 \pm 13.12$ & $37.78-52.93$ & $46.50 \pm 7.20 \|$ & $41.92-51.08$ & $51.20 \pm 3.33 \|$ & $48.82-53.58$ & $49.20 \pm 6.55$ & $44.52-53.88$ & $49.89 \pm 6.79$ & $44.67-55.11$ \\
\hline Activity & $22.07 \pm 8.62$ & $17.09-27.05$ & $24.50 \pm 6.64 \mathrm{II}$ & $20.28-28.72$ & $29.20 \pm 3.39$ II & $26.77-31.63$ & $27.00 \pm 5.27$ & $23.23-30.77$ & $27.56 \pm 4.36$ & $24.20-30.91$ \\
\hline Asthma control & $12.86 \pm 2.57$ & $11.37-14.34$ & $13.58 \pm 2.68$ & $11.88-15.29$ & $14.60 \pm 0.84$ & $14.00-15.20$ & $14.90 \pm 1.20$ & $14.04-15.76$ & $14.89 \pm 1.05$ & $14.07-15.70$ \\
\hline
\end{tabular}

\footnotetext{
* $P=.01$ asthma knowledge, comparing camp vs 3 months.

$\dagger P=.003$ asthma self-efficacy, comparing baseline vs camp.

$\ddagger P=.049$ asthma self-efficacy, comparing camp vs 3 months

$\S P=.005$ quality of life-total, comparing camp vs 3 months.

$\| P=.002$ quality of life-emotion, comparing camp vs 3 months.

II $P=.003$ quality of life-activity, comparing camp vs 3 months
}

throughout the follow-ups, and in most cases the increasing trends either slowed or reversed slightly at the 6-month follow-up and onward.

\section{Discussion}

This study supports adolescents' receptiveness of a peerled asthma program and peer leaders. We found that adolescents who participated in the peer-led program reported greater satisfaction, enjoyment, and usefulness of the program in dealing with asthma than those in the adult-led program. In particular, it is noteworthy that the peer-led group's perception of the camp being "fun" was greater than their counterparts (91\% vs $60 \%$ ), while both groups were offered comparable recreational activities. The "fun" factor was particularly important in engaging the adolescent audience in the program, and may be responsible for higher program satisfaction that was subsequently translated into greater improvements in asthma outcomes in the peer-led group..$^{21}$ This study seems to echo other studies ${ }^{9}$ that have reported adolescents' partiality to health programs led by their own peers instead of adult experts. The peer-led group also viewed their leaders' qualifications favorably in regard to credibility, warmth, and similarities. Similarities between leaders and learners have been considered the core of a peer-led program and pivotal in increasing the learners' receptiveness to the message being delivered. 3,34

As such, our peer-led program was able to offer and capitalize on this key asset. Most participants agreed on the peer leaders' ability to provide useful information, but fewer agreed on the leaders' capacity to engage in open communication and address the participant's emotional needs. The learner feedback underscores the needs for a training curriculum that could strengthen peer leaders' communication skills and emotional intelligence. Perhaps emotional intelligence can be considered a criterion in select- ing peer leaders in the future. In addition, participants in both groups appreciated the opportunity to meet with other teens with asthma throughout the program. It seems important to provide the context in which adolescents can feel connected and interact with other teens who share similar burdens due to the disease. Such a context affords not only a chance to exchange information and experiences about asthma with each other, but also provides psychosocial benefits by fostering a sense of normalcy and promoting positive identity.

This study shows that peer leaders can benefit from the peer-led program. The peer leaders consistently reported improved asthma knowledge, self-efficacy, emotional wellbeing, activity levels, and asthma control during the study participation. Improvements in outcome variables over time in peer leaders produced large effect sizes indicating clinically meaningful changes. ${ }^{32,33}$ The demonstrated benefits to peer leaders are in concurrence with other studies ${ }^{9,18,35-37}$ that addressed a variety of health issues in adolescents by using peer leaders. In an earlier study, ${ }^{35}$ peer leaders benefited more from the intervention than adolescent learners, and the researchers attributed the differences to the peer leaders' greater exposure to education content.

Preparing for and assuming leadership roles may have also contributed to positive outcomes in peer leaders, as it fosters positive attitudes and solidifies gained knowledge by sharing with others. ${ }^{18}$ On the other hand, Olsson et al ${ }^{37}$ understood peer leaders' benefits in light of increasing self-awareness and fulfillment of altruistic desires by helping others, through which the teen leaders become more capable in managing challenges associated with their own health issues. We speculate that improvements in asthma outcomes in the peer leaders may be due to the intensive training sessions and their first-hand experience as a leader, which allowed them to internalize the learned information by sharing with their peers. The rewarding experience as a 
leader could also have reinforced positive changes in peer leaders' self-management beliefs and behaviors.

It is noteworthy that the increasing trends in outcomes in peer leaders either plateaued or slightly decreased at 6 and 9 months after camp. This underscores the needs for a peer leader booster session to ensure the long-term sustainability of the program impact on peer leaders. The benefits of a booster program in improving knowledge, self-efficacy, and quality of life in peer leaders can ultimately translate into ensuring long-term positive effects of a peer-led program involving periodical contacts between the peer leaders and learners, such as in this study. A booster or refresher training for peer leaders has been advocated because of its value in renewing the leaders' enthusiasm, as well as providing an opportunity to interact with adult supervisors who can help the leaders manage ongoing issues and ensure the integrity of the information being delivered. ${ }^{13,35}$ In this study a booster session could have been valuable in addressing challenges that the peer leaders encountered in making follow-up contacts with their group members. Given our data, a booster session at 6 months after the implementation of the program seems reasonable. A future study is warranted to examine the effects of a booster session on overall program success.

This study has several limitations. First, program and peer leader evaluation data were collected anonymously, to solicit unbiased opinions. Therefore we were unable to identify characteristics of adolescents who were least receptive of or dissatisfied with the program or peer leaders. Second, the benefits of the program to peer leaders must be interpreted with caution. The modest changes in actual mean scores raise a question regarding the extent of how clinically meaningful the changes were. Future research is needed to determine the clinical importance of the magnitude of observed changes, by examining its associations with relevant clinical indices, such as the number of symptom free days or urgent healthcare use due to asthma.

Furthermore, this study is limited in explaining the mechanisms underlying the improvements in the peer leaders. Peer leader training sessions took place before the camp, and data were not collected until after the camp. Therefore, it is unclear whether the improvements were the result of the training sessions or leadership experience at camp, which may have heightened a sense of confidence and given the opportunity to internalize the learned information by sharing with others. A future study can address this shortcoming by adding a data point immediately after training but before the camp, to understand the extent to which each component (ie, training vs leadership experience) is responsible for the improvement. In addition, the peer leaders were predominantly female and white. Such homogeneity of the peer leaders may have diminished the sense of similarities with the peer leaders perceived by males or non-white participants. Strategies to recruit and engage qualified male and more racially diverse adolescents as peer leaders need to be explored and implemented for future research.

\section{Conclusions}

Adolescence is an important period for asthma selfmanagement training as daily responsibilities of disease management are gradually transferred from parents to adolescents. As such, equipping adolescents to assume the responsibilities through appropriate training is essential. This study provides empirical evidence that a peer-leader approach is an alternative to conventional programs offered by health professionals and is well received by adolescents. Such programs capitalize on peer dynamics as well as recognize adolescents' desire to be independent of authority figures, thus rendering developmental relevance. The study demonstrates that adolescents with asthma, after adequate training, can serve as leaders who can reach out and assist their peers with asthma. However, clinicians are still an integral part of this type of program, as they are well situated to identify and train qualified peer leaders. Clinicians can also offer ongoing supervision and support for peer leaders and their activities. In doing so, the clinicians' efforts to establish and foster mutual trust and a sense of partnership with the peer leaders are essential. Organized collaboration between the clinicians and peer leaders in an asthma program such as this can potentially have positive impact on asthma management in adolescents.

\section{ACKNOWLEDGMENTS}

We would like to thank Judith Brasch for coordinating the project and providing helpful comments on the paper, and study participants for providing the study team with invaluable data.

\section{REFERENCES}

1. Ozer EJ, Weinstein RS, Maslach C, Siegel D. Adolescent AIDS prevention in context: the impact of peer educator qualities and classroom environments on intervention efficacy. Am J Community Psychol 1997;25(3):289-323.

2. Parcel GS, Simons-Morton BG, Kolbe LJ. Health promotion: integrating organizational change and student learning strategies. Health Edu Q 1988;15(4):436-450.

3. Bandura A. Social foundation of thoughts and action. Englewood Cliffs, NJ: Prentice-Hall; 1986.

4. Zimbardo PG, Leippe MR. The psychology of attitude change and social influence. New York: McGraw-Hill; 1991.

5. Kyngas H. Support network of adolescents with chronic disease: adolescents' perspective. Nurs Health Sci 2004;6(4):287-293.

6. Velsor-Friedrich B, Vlasses F, Moberly J, Coover L. Talking with teens about asthma management. J Sch Nurs 2004;20(3):140-148.

7. Balfour-Lynn L. Growth and childhood asthma. Arch Dis Child 1986;61(11):1049-1055. 


\section{Evaluation of a Peer-Led Asthma Self-Management Program}

8. Cohen R, Franco K, Motlow F, Reznik M, Ozuah PO. Perceptions and attitudes of adolescents with asthma. J Asthma 2003;40(2):207211.

9. Stephenson J, Strenge V, Copas A, et al. The long-term effects of a peer-led sex education programme (RIPPLE): a cluster randomised trial in schools in England. PLoS Med 2008;5(11):1575-1590.

10. Cartagena RG, Veugelers PJ, Kipp W, Magigav K, Laing LM. Effectiveness of an HIV prevention program for secondary school students in mongolia. J Adolesc Health 2006;39(6):925.e9-e16.

11. Lo E, Coles R, Humbert ML, Polowski J, Henry CJ, Whiting SJ. Beverage intake improvement by high school students in Saskatchewan, Canada. Nutr Res 2008;28(3):144-150.

12. Mahat G, Scoloveno MA, De Leon T, Frenkel J. Preliminary evidence of an adolescent HIV/AIDS peer education program. J Pediatr Nurs 2008;23(5):358-363.

13. Maticka-Tyndale E, Barnett JP. Peer-led interventions to reduce HIV risk of youth: a review. Eval Program Plann 2010;33(2):98-112.

14. Mellanby AR, Rees JB, Tripp JH. Peer-led and adult-led school health education: a critical review of available comparative research. Health Educ Res 2000;15(5):533-545.

15. Backett-Milburn K, Wilson S. Understanding peer education: insights from a process evaluation. Health Educ Res 2000;15(1):85-96.

16. Ochieng BM. Adolescent health promotion: the value of being a peer leader in a health education/promotion peer education program. Health Educ J 2003;62(1):61-72.

17. Audrey S, Holliday J, Campbell R. It's good to talk: adolescent perspectives of an informal, peer-led intervention to reduce smoking. Soc Sci Med 2006;63(2):320-334.

18. Fongkaew W, Fongkaew K, Suchaxaya P. Early adolescent peer leader development in HIV prevention using youth-adult partnership with schools approach. J Assoc Nurses AIDS Care 2007;18(2):6071.

19. Pearlman DN, Camberg L, Wallace LJ, Symons P, Finison L. Tapping youth as agents for change: evaluation of a peer leadership HIV/AIDS intervention. J Adolesc Health 2002;31(1):31-39.

20. Shah S, Peat JK, Mazurski EJ, Wang H, Sindhusake D, Bruce C, et al. Effect of peer led programme for asthma education in adolescents: cluster randomised controlled trial. BMJ 2001;322(583):1-5.

21. Rhee H, Belyea MJ, Hunt JF, Brasch J. Effects of a peer-led asthma self-management program for adolescents. Arch Pediatr Adolesc Med 2011;165(6):513-519.

22. National Heart, Lung, and Blood Institute. Expert panel report 3: Guidelines for the diagnosis and management of asthma. Bethesda, MD: NHLBI; 2007.

23. Asthma and Allergy Foundation of America. Power breathing program: facilitator's handbook. Landover, MD: AAFA; 2006.
24. Procidano ME, Heller K. Measures of perceived social support from friends and from family: three validation studies. Am J Community Psychol 1983;11(1):1-24.

25. Bartholomew LK, Gold RS, Parcel GS, Czyzewski DI, Sockrider MM, Fernandez M, et al. Watch, discover, think and act: evaluation of computer-assisted instruction to improve asthma self-management in inner-city children. Patient Educ Couns 2000;39(2-3):269-280.

26. Bursch B, Schwankovsky L, Gilbert J, Zeiger R. Construction and validation of four childhood asthma self-management scales: parent barriers, child and parent self-efficacy, and parent belief in treatment efficacy. J Asthma 1999;36(1):115-128.

27. Zebracki K, Drotar D. Outcome expectancy and self-efficacy in adolescent asthma self-management. Child Health Care 2004;33(2): 133-149.

28. Juniper EF, Guyatt GH, Feeny DH, Ferrie PJ, Griffith LE, Townsend M. Measuring quality of life in children with asthma. Qual Life Res 1996;5(1):35-46.

29. Okelo SO, Wu AW, Krishnann JA, Rand CS, Skinner EA, Diette GB. Emotional quality-of-life and outcomes in adolescents with asthma. J Pediatr 2004;145(4):523-529.

30. Tauler E, Vilagut G, Grau G, et al. The Spanish version of the paediatric asthma quality of life questionnaire (PAQLQ): metric characteristics and equivalence with the original version. Qual Life Res 2001;10(1):81-91.

31. Cohen J. Statistical power analysis for the behavioral sciences, 2nd edition. Hillsdale, NJ: Lawrence Erlbaum; 1988.

32. Norman GR, Sloan JA, Wyrwich KW. Interpretation of changes in health-related quality of life: the remarkable universality of half a standard deviation. Med Care 2003;41(5):582-592.

33. Sloan JA, Cella D, Hays RD. Clinical significance of patient-reported questionnaire data: another step toward consensus. J Clin Epidemiol 2005;58(12):1217-1219.

34. Milburn K. A critical review of peer education with young people with particular reference to sexual health. Health Educ Res 1995; 10(4):407-420

35. Becker CB, Bull S, Smith LM, Ciao AC. Effects of being a peerleader in an eating disorder prevention program: can we further reduce eating disorder risk factors? Eat Disord 2008;16(5):444-459.

36. Wyman PA, Brown CH, LoMurray M, et al. An outcome evaluation of the sources of strength suicide prevention program delivered by adolescent peer leaders in high schools. Am J Public Health 2010; 100(9):1653-1661.

37. Olsson CA, Boyce MF, Toumbourou JW, Sawyer SM. The role of peer support in facilitating psychosocial adjustment to chronic illness in adolescence. Clin Child Psychol Psychiatry 2005;10(1):78-87. 